\title{
Five-year workplace wellness intervention in the NHS
}

Holly Blake

Division of Nursing, Queen's Medical Centre, Nottingham NG7 2HA, UK

Email:Holly.Blake@nottingham.ac.uk

Dingyuan Zhou

Institute for Work, Health and Organisations, University of Nottingham, UK

Mark E Batt

Centre for Sports Medicine, Nottingham University Hospitals NHS Trust, UK

\begin{abstract}
Aims: Poor health and well-being has been observed among NHS staff and has become a key focus in current public health policy. The objective of this study was to deliver and evaluate a five-year employee wellness programme aimed at improving the health and well-being of employees in a large NHS workplace.
\end{abstract}

Method: A theory-driven multi-level ecological workplace wellness intervention was delivered including health campaigns, provision of facilities and health-promotion activities to encourage employees to make healthy lifestyle choices and sustained behaviour changes. An employee questionnaire survey was distributed at baseline (n $=1,452)$ and at five years $(\mathrm{n}=1,134)$, including measures of physical activity, BMI, diet, self-efficacy, social support, perceived gen- eral health and mood, smoking 
behaviours, self-reported sickness absence, perceived work performance and job satisfaction.

Results: Samples were comparable at baseline and follow-up. At five years, significantly more respondents actively travelled (by walking or cycling both to work and for non-work trips) and more were active while at work. Significantly more respondents met current recommendations for physical activity at five years than at baseline. Fewer employers reported 'lack of time' as a barrier to being physically active following the intervention. Significantly lower sickness absence, greater job satisfaction and greater organisational commitment was reported at five years than at baseline.

Conclusions: Improvements in health behaviours, reductions in sickness absence and improvements in job satisfaction and organisational commitment were observed following five years of a workplace wellness intervention for NHS employees. These findings suggest that health-promoting programmes should be embedded within NHS infrastructure.

\section{INTRODUCTION}

Globally, and in the UK, the workplace has been identified as a priority setting for workplace health promotion [1-4] and the number of organisations offering wellness programmes is on the increase. Worksites not only provide longitudinal access to a large number of people but have prospect for multi-level 'ecological' interventions directed at individual, organisational and environmental determinants of health behaviours.[5-7] The evidence suggests that a well-implemented multi- component 
health-promotion programme can not only improve the health status of participants but can also improve work-related outcomes such as productivity and sickness absence rates.[8] This creates a sound argument for the financial sustainability of workplace wellness programmes, particularly those that encompass initial resource investment and top- level managerial support.[6,9] Government publications have called for National Health Service (NHS) workplaces to 'set the example' for population health; [3] however, sickness absence rates are known to be higher in the NHS than other sectors [10] and recent evidence shows that NHS workers continue to exhibit a rela- tively poor health profile [11-13] despite being perceived by the general public as role models for health.[14-16] This requires immediate public health action, not only to ensure a healthy public health workforce for the future, but also because ill health in NHS staff may negatively impact upon the quality of patient care, $[17,18]$ and because the health practices of health care staff have been associated with their tendency to raise health behaviour issues with their clients.[19] To this end, we report the findings of the delivery and evaluation of a large-scale workplace wellness programme, implemented over five years, in an NHS setting.

\section{METHODS}

\section{Needs analysis and intervention development}

An initial employee needs analysis and employee health and well-being survey demonstrated a poor health profile of NHS employees in this setting and provided user-led baseline data that would inform health professionals, managers and policy makers of areas that could be targeted for health intervention. A needs-based, theorydriven intervention was developed, based on the ecological model of health.[20] The ecological approach involves targeting a population at all levels by implementing new policies, by providing opportunities for making healthy lifestyle choices in the 
physical environment, by manipulating the human environment (through community interventions and social support) and by empowering and informing the individual through information dissemination and individual incentives.[21] The intervention was targeted towards improving the health and well-being of NHS employees and had top-level management support within the local NHS trust, a dedicated NHS health and well-being champion to deliver the intervention, and significant capital and revenue funding, all of which have been identified as important factors in suc- cessful wellness interventions.[6]

\section{The workplace wellness programme}

Following a three-month launch period, an intervention was delivered over a fiveyear period from 2006 to 2011, accessible to over 7,000 employees in early 2006 and more than 13,000 from April 2006 to 2011 following a trust merger. The intervention was a 'branded' employee wellness programme that included a dedicated website and exercise class timetable (e.g. yoga, pilates, hula hoop, dancing, tai chi, boxercise) and exercise sessions (e.g. touch rugby, netball, pedometer challenges), a staff gym, dedicated well-being and exercise rooms, cycle storage and showers, staff cycle schemes, dietary interventions (e.g. slimming classes, healthy eating schemes), regular health campaigns (e.g. active commuting, Wellbeing Week, Mental Health Week), community interventions (e.g. competitions, local sports clubs and gym membership, Nordic walking), health education, access to health screening checks, and a range of complementary and relaxation therapies (e.g. massage, meditation). The primary focus at the outset was on the promotion of physical activity, with additional activities offered according to staff demand and capacity of the team; as such, the programme evolved over time, although a summary of key activities by year is provided in Table 1 (Available at: http:// pph.sagepub.com/supplemental). 
Incentives were not provided for participation in the majority of the activities, including structured exercise sessions, gym attendance, dietary interventions and therapies. On occasion, prize incentives were provided for team-based com- petition activities such as the pedometer challenge, or in specific health campaigns; for example, during one particular week-long campaign, free breakfast vouchers were provided to staff who cycled to work.

Services and facilities were promoted with the support of local 'workplace health champions' -individual employees who recognise the importance of employee health and well- being, and who actively promote health behaviours within the organisation.[22] In this instance, workplace health champions undertook their role during working hours as part of their paid employment supported by a signed contract with their employer, being released from their job roles to undertake related activities for a specified number of hours per month, which was agreed with their line managers.

\section{Pre- and post-intervention}

Ethical approval and local research governance approval was granted by the Central Office for Research Ethics Committees and the local NHS trust. All NHS employees at the participating organisation were invited to complete a questionnaire survey before $(n=7,065)$ and five years after $(n=13,606)$, the intervention (the increase in total employee numbers is due to a trust merger mid-2006). The questionnaire included demographic items (age, gender, body mass index (BMI)) and items relating to physical activity, dietary habits, self-efficacy for physical activity and diet, social support for physical activity and diet, general health, mood, smoking, work performance, job satisfaction and sickness absence. The measures were adapted from a tool provided to service managers by the funder of the intervention, which had been 
produced elsewhere for a national workplace health initiative.[7] The adapted measures used here have been used with other health care samples and are described more fully elsewhere.[11-13]

Physical activity measurement included assessment of incidental physical activity, sitting time, sport and recreational physical activity. Physical activity level was measured using the modified International Physical Activity Questionnaire [23] and a list of 20 common barriers to being physically active. Self-efficacy for physical activity and knowledge of physical activity were each measured using a five-item scale; social support for physical activity was measured using a four-item scale. Participants were asked to rate their general health on a six-point Likert scale ( 0 being very poor and 5 being excellent). The 12-item General Health Questionnaire (GHQ12) was used to measure mood of employees, with a cut-off point of $2 / 3$ to indicate low mood.[24] Participants were asked how often they got seven hours of sleep per night on a four-point Likert scale (1 being seldom or never, 4 being always). Employees were asked whether they smoked a cigarette or pipe; knowledge about dangers of passive smoking was assessed by a single item: 'Do you think that breathing someone else's smoke is dangerous to your health?' The diet of employees was measured by the following items: 'Do you eat five servings of fruit/vegetables a day?'; 'Do you eat foods high in fat and sugar?'. Employees were also asked to indicate whether they considered that they ate healthily at the time of the study. Self- efficacy for healthy eating was measured using an eightitem scale; social support for healthy eating was measured by a four-item scale. Perceived work performance over the previous four weeks was measured by a single item, rated on a six-point Likert scale ( 0 being my worse performance, 5 being my 
best performance). Participants were asked to self-report on their frequency of sickness absence.

Questionnaires were distributed to employees in the following occupational groups via their payslips: Admin \& Clerical/Senior Managers; Allied Health Professionals; Ancillary; Dental; Maintenance; Medical; Nursing \& Midwifery; Scientific \& Professional; and Technicians. Completion was voluntary and anonymous; employees were asked to return their questionnaires to a researcher who was not employed by the same organisation, via the internal mail system, within a four-week period. Informed consent was taken to be return of the form. Data were then entered into SPSS for Windows 18.0 and a $10 \%$ data check was conducted.

\section{RESULTS}

Questionnaires were completed by 1,452 employees at baseline and 1,134 employees at five-year follow-up. There were no significant differences between baseline and follow-up samples in participant characteristics, including age, gender, ethnicity, living arrangements, work status (full-time/part-time) and reported long-term health issues. Comparison of demographic information between baseline and follow-up is presented in Table 2 .

\section{Physical activity}

Significantly more respondents considered themselves either very or fairly 'active at work' at follow-up than at baseline $(69.7 \%$ and 53.9\%, respectively; Cramer's V = $0.18, \mathrm{p}<.001)$

Significantly more respondents at follow-up reported actively travelling (walking or cycling) to the workplace in the previous seven days (37.6\%) than at baseline $(30.7 \%)$ $(\varphi=-0.07, \mathrm{p}<.001)$. Additionally, participants who actively travelled at follow-up spent significantly more time walking or cycling in a typical trip to or from work than 
participants who reported actively travelling at baseline (Cramer's V $=0.24, p<$ $.001)$

With regards to active travel during leisure time, significantly more participants at follow-up than at baseline reported having walked or cycled for at least 10 minutes (for trips outside of work travel) in the previous seven days $(70.1 \%$ and $65.1 \%$, respectively; $\varphi=-0.05, \mathrm{p}=.007)$.

Respondents were categorized according to whether they reported meeting the recommended daily level of physical activity at the time of the study ('30 minutes of moderate physical activity on most days of the week'). Those participants who met the recommended level of physical activity were defined here as 'active', and those who did not meet these criteria were defined here as 'less active'. According to these criteria, there was a significant improvement in the proportion of participants who reported meeting physical activity guidelines from baseline to follow-up (56.4\% and $60.5 \%$, respectively; $\varphi=0.14, \mathrm{p}<.001)$.

2 (time: baseline and follow-up) $\times 2$ (activeness: less active and active) betweensubjects analysis of variance (ANOVA) was carried out on incidental physical activity (e.g. stair use, moving around while on the phone, walking to speak to colleagues rather than telephoning); sports and recreational activity; the time spent sitting down (travelling, watching TV/video/DVD/cinema, using computer, reading, chatting, socialising, listening to music, playing games) and moving about (e.g. gardening and housework) on a typical work and non- work day; self-efficacy for engaging in physical activity; knowledge about physical activity; self-efficacy for healthy eating; support for engaging in physical activity; support for healthy eating; job satisfaction and commitment to working in the NHS trust (Table 3). 
ANOVA showed that respondents at follow-up engaged in significantly more incidental physical activities than respondents at baseline $(\mathrm{F}(1,2287)=56.5, \mathrm{p}<.001$, partial $\eta 2=0.02$ ) and that the active respondents engaged in significantly more incidental physical activities than the less active respondents $(F(2,2287)=50.2$, p < .001 , partial $\eta 2=0.04)$

Respondents at follow-up reported spending significantly less time sitting $(F(1,2149)$ $=4.9, \mathrm{p}<.001$, partial $\eta 2=.14)$ and more time moving about than respondents at baseline $(F(1,2149=9.8, p<.001$, partial $\eta 2=0.17)$. As might be expected, active respondents tended to spend less time sitting $(\mathrm{F}(2,2149)=3.6, \mathrm{p}=.03$, partial $\eta 2=$ 0.003) than the less active respondents.

Active respondents reported greater self-efficacy for physical activity than less active respondents $(\mathrm{F}(1,2505)=214.33, \mathrm{p}<.001$, partial $\eta 2=0.15)$. However, there were no significant differences between baseline and follow-up on knowledge about physical activity, self- efficacy for physical activity or self-efficacy for healthy eating. Active respondents reported receiving significantly more social support for both physical activity and healthy eating than the less active respondents $(\mathrm{F}(2,2028)=$ 26.4, $\mathrm{p}<.001$, partial $\eta 2=0.03 ; \mathrm{F}(2,2050)=6.9, \mathrm{p}<.001$, partial $\eta 2=0.007)$. However, there were no significant differences in social support between respondents at baseline and follow-up.

Those respondents who were more active reported higher levels of satisfaction with their job than the less active respondents $(\mathrm{F}(2.2529)=7.7, \mathrm{p}<.001$, partial $\eta 2=$ 0.006). Significantly more respondents at follow-up reported being satisfied with their job $(F(1,2529=11.0, p<.001$, partial $\eta 2=0.004)$ and feeling committed to working for the trust $(\mathrm{F}(1,2301)=5.7, \mathrm{p}=.02$, partial $\eta 2=0.002)$ than respondents at baseline. 
Perceived commitment to the trust did not differ between active and less active respondents.

\section{Barriers to physical activity}

The most common reported barriers to engaging in physical activity were similar at both time points and four factors were frequently identified at both baseline and follow-up: lack of time to be physically active; feeling too tired; a lack of motivation to be active; and feeling the need to rest and relax in their spare time. Significantly fewer participants reported 'lack of time' as a barrier at follow-up compared with baseline $(\varphi=-0.04, p=.03)$. Statistical comparison of reported barriers at baseline and follow-up is presented in Table 4.

\section{General health and mood}

Although the proportion of respondents reporting low mood was lower at follow-up $(8.9 \%)$ compared with baseline $(12.1 \%)$, this trend was not statistically significant $(\varphi=$ 0.01). However, the active respondents reported significantly better mood $(\mathrm{F}(2,2476)$ $=10.4, \mathrm{p}<.001$, partial $\eta 2=.008)$ than the less active respondents. Two-way (time $\mathrm{x}$ activeness) between-subject ANOVA on mood status showed that the main effects of timeline and activeness were not significant.

At both baseline and follow-up, the active respondents were more likely to report good health than the less active respondents (Cramer's V $=0.17, \mathrm{p}<.001$; Cramer's $\mathrm{V}=0.26, \mathrm{p}<.001)$. However, overall there was no significant difference in selfreported general health between baseline and follow-up (Cramer's V $=0.06, \mathrm{p}=.12$ ). The proportion of staff reporting that they had seven hours of sleep more than half of the time increased from $59.6 \%$ at baseline to $61.7 \%$ at follow-up, although this difference did not reach statistical significance (Cramer's $V=0.04, p=.24$ ). Those 
respondents who reported getting seven hours of sleep more than half of the time were more likely to be active than those who did not (Cramer's $\mathrm{V}=0.14, \mathrm{p}<.001)$.

\section{Smoking behaviour}

The proportion of current smokers reduced from $10.5 \%$ of the sample at baseline to $8.6 \%$ at follow-up, although this difference did not reach statistical significance $(\varphi=$ $0.03, \mathrm{p}=.12$ ). Although there were no significant differences at baseline (Cramer's $\mathrm{V}$ $=0.05, \mathrm{p}=.17)$, the active respondents were less likely to smoke than inactive respondents at follow-up (Cramer's $\mathrm{V}=0.14, \mathrm{p}<.001)$. The majority $(95.7 \%$ and $94.1 \%$ at base- line and follow-up, respectively) of the respondents agreed that passive smoking was dangerous to health.

\section{Weight and dietary behaviours}

There were no significant differences in $\mathrm{BMI}$ between baseline $(\mathrm{M}=25.2, \mathrm{SD}=4.9$, range $=11.2-60)$ and follow-up $(\mathrm{M}=25.4, \mathrm{SD}=5.9$, range $=11.5-68.4)$. Overall, the active respondents had significantly lower BMI $(\mathrm{F}(2,2275=6, \mathrm{p}=.003$, partial $\eta 2=$ 0.005) than the less active respondents. Two-way (time $\mathrm{x}$ activeness) betweensubjects ANOVA on BMI showed that the main effects of timeline and activeness were not significant. Participants were grouped into weight categories using the clinical classification of BMI: $<18.5$ = underweight; 18.5-25.0 = normal weight; 25.0-30.0 = overweight; $>30=$ obese. The percent- age of obese respondents at baseline and follow-up was similar (13\% and 12.5\%). Although there were no statistically significant differences in overweight and obesity, the proportion of overweight respondents was lower at follow-up (26.3\%) than at baseline (30.3\%). More than half of the respondents reported that they did not consume five servings of fruit/vegetables per day and this figure increased from baseline to follow-up, although the difference did not reach statistical significance $(56.9 \%$ at baseline, $61.1 \%$ at 
follow-up). There were significantly fewer participants at the time of the follow-up $(54.9 \%)$ than at baseline $(63.4 \%)$ who reported that they intended to increase the amount of fruit/vegetables that they consumed in the next year (Cramer's $V=0.11$, $\mathrm{p}<.001)$.

More than one-third of the employees at both baseline and follow-up reported that they ate foods high in fat and sugar at least once a day $(30.2 \%$ and $29.0 \%$ for once a day; $7.0 \%$ and $8.8 \%$ for two to three times a day, respectively), with no significant difference between time points. However, the proportion of respondents consuming sugary foods every day significantly decreased from $13.5 \%$ at baseline to $9.9 \%$ at follow-up (Cramer's $\mathrm{V}=0.06, \mathrm{p}=.01)$.

There was no significant difference in reported daily water consumption from baseline to follow-up, with around one- fifth of both baseline and follow-up participants reporting that they drank eight glasses of water a day. There was no significant difference in respondents' perceptions of healthy eating $(\varphi=-0.03, p=$ $.22)$, with a large proportion of employees $(70.6 \%$ and $72.8 \%$ at baseline and followup, respectively) perceiving that that they were eating healthily at both time points. However, intention to eat more healthily reduced over the five years, with significantly fewer participants intending to eat more healthily in the next six months at follow-up $(71.3 \%)$ than at baseline $(79.5 \%)(\varphi=0.09, \mathrm{p}<.001)$.

Compared with baseline (69.9\%), significantly more respondents reported that they consumed food in the onsite staff restaurant at follow-up $(73.8 \%)(\varphi=0.04, p=.03)$. Significantly more participants reported the availability of healthy food choices in the staff restaurant at follow- up than at baseline $(\mathrm{t}=7.59, \mathrm{df}=688, \mathrm{p}<.001, \eta 2=0.08)$. Of those who used the staff restaurant, respondents at follow-up were more likely to perceive that the trust had a culture of healthy eating than were respondents at 
baseline $(\mathrm{t}=3.06, \mathrm{df}=534, \mathrm{p}=.002, \eta 2=0.017)$, although this difference in perception was not evident in those who did not actually eat in the facilities $(\mathrm{t}=1.47$, $\mathrm{df}=1163, \mathrm{p}=.14)$. Overall, participants at follow-up seemed to rate the nutrition culture of the trust more positively than those at baseline $(\mathrm{t}=3.31, \mathrm{df}=1729$, $\mathrm{p}=.001, \eta 2=.001)$

\section{Work performance and sickness absence}

The majority of the respondents at both time points $(92.3 \%$ and $93.5 \%$ at baseline and follow-up, respectively) reported that they were satisfied with their overall performance at work; this did not significantly differ between baseline and follow-up. Reported sickness absence levels for the previous month significantly reduced from $4.9 \%$ at baseline to $2.6 \%$ at follow- up (Cramer's $\mathrm{V}=0.13, \mathrm{p}<.001)$.

\section{DISCUSSION}

This work supports the global and national public health drive to improve health behaviours and promote physical activity in the workplace setting [1-3] and in NHS employees specifically. [3,11-13] To our knowledge, this is the first large-scale, theory-driven employee wellness programme delivered over five years in an acute NHS workplace. Particularly at the outset, the intervention was primarily targeted towards the promotion of physical activity but developed over time to incorporate the promotion of other health behaviours including healthy diet, smoking cessation and well-being. Findings showed that following five years of multi-level ecological intervention, the proportion of employees reporting that they met government recommendations for physical activity had increased. The proportion of employees reporting that they actively travelled (walked or cycled), both to the workplace and in their leisure time, had increased. The proportion of respondents engaging in incidental 
physical activities had increased over the five years, and sedentary behaviour ('time spent sitting') had reduced. These findings are imperative given the known association between physical activity, mortality and chronic disease. [25-27] Our findings lend support to previous studies that have shown modest improvements in physical activity following workplace intervention, [28] and add to the emerging, but limited, evidence base for physical activity interventions delivered in hospital settings, where interventions of shorter duration have been delivered to considerably smaller populations and have shown significant increases in physical activity. [29,30] The observed increases in the proportion of individuals who actively travelled both in work and leisure time has relevance for population health; however, research has shown that while people value the incidental health benefit associated with active travel, they are often motivated less by physical activity but perhaps more by convenience, speed, cost and reliability when selecting modes of travel; [31] this has implications for the promotion of active travel in the workplace.

Although this study lacked objective measurement of physical activity, and selfreports may be subject to recall bias, it has been found that self-reports may correlate with objective measures of total energy expenditure. [32] Nevertheless, it is recommended that researchers may consider using device-based measures in future studies to measure physical activity levels, total sedentary time and patterns of sedentary time accumulation, as well as measuring physiological parameters that have a known influence on risk of chronic disease.

The findings demonstrate that employees who were more active (met the recommended levels of daily physical activity) had higher self-efficacy, or confidence, and greater perceived social support for physical activity. Wellness programmes may therefore be more effective if they include interventions that are 
designed to enhance social support and increase self-efficacy for physical activity, since both factors have previously been identified as important predictors of physical activity specifically among health care staff.33 Compared with those who were less active, the more active employees also had lower BMI and better mood, reported better general health, were more satisfied with their jobs, reported more sleep, and were less likely to smoke. These findings support observations that health behaviours often 'cluster' together in individuals [34] and suggest that a holistic approach to behaviour change may be best adopted by workplace wellness programmes by targeting multiple 'unhealthy behaviours' or lifestyle risk factors.

No significant improvements were observed in employee knowledge about physical activity and diet after five years; this suggests that there may be a need for raising awareness about health issues, which may be achievable through improved accessibility of health information to employees, and increasing the provision of workshops, training sessions or events on health and well-being.

The most commonly reported barrier to physical activity in our sample was lack of time; this is consistent with previous work- place intervention studies, which have identified that scheduling and work conflicts are often the most common barriers concerning time. [35] We recommend that interventions and services that encourage healthy lifestyle choices should be designed to be easily accessible for employees, by working towards policy changes such as protected work breaks, encouraging incidental physical activities (such as stair use) and offering activities that are accessible to all employees, including those with rotating work schedules. Our intervention evolved over time as many modifiable behavioural determinants of healthy living were identified at the outset and addressed (e.g. developing brief exercise classes to fit within lunch breaks, providing access to gym facilities onsite, 
making alterations to class booking and payment systems to increase convenience to staff). Addressing barriers as part of this process may help to explain the observed reduction from baseline to follow-up in the proportion of employees reporting 'lack of time' as a barrier to physical activity.

While incentives for participation were not provided for the majority of activities over the five years, those physical activities with a competition or a team-based element (e.g. pedometer challenge) occasionally included a 'prize' for winning teams.

Although this may have increased the number of individuals participating in particular physical activities, evaluation of these activities has revealed that participants felt more motivated by the health benefits, competitive element or the social nature of the activity rather than a prize incentive. Motivators for employee engagement (or not) in particular activities offered by multi-component programmes warrants further investigation.

The proportion of employees who smoked reduced over the five years, although this observed reduction was not statistically significant. Rates at both baseline and five years were considerably lower than the national smoking prevalence figure for the general adult population in the UK, which was reported to be around $21 \%$ for 2007 . [36] Low smoking rates in this population are promising, yet may be attributed to an overall decrease in smoking prevalence in the UK and also smoking ban policies implemented in public places and workplaces around the start of the intervention, [37] including the local NHS trust where the survey took place. [38] Historically, higher rates of sickness absence have been observed in the NHS compared with other sectors $[39,40]$ and therefore the reduction in self-reported sickness absence observed here was notable. Although sickness absence 
was self-reported in our sample, good agreement has been found between selfreported and register information in public-sector employee sickness absence rates.[41] Furthermore, our baseline figures were comparable both with local trust rates and also the sick- ness absence rate reported in the NHS at this time. [10] Our sickness absence rate at five years was substantially lower than 2011 national figures (4.24\%). [39] Although we recognise the limitations of study design, this reduction may reflect our observed moderate improvements in some health behaviours and also a range of additional factors, not least the increase in job satisfaction and commitment to the NHS trust as an employer that was observed at the five-year follow- up. While the determinants of such factors are clearly complex, provision of services and facilities that promote employee health and wellbeing are already known to be associated with additional benefits for both the employee and the organisations that stretch beyond health behaviours. $[6,9,42]$ Indeed, the promotion of physical activity, for example, has been proposed as a strategic corporate priority to improve both employee health and business performance. [43]

Estimates of overweight and obesity should be interpreted with caution due to the use of self-reported weight and height to calculate BMI. The tendency to overestimate height and underestimate body weight means that BMI may be underestimated, particularly in males and in those who are overweight. [44] However, the majority of the sample and population were female and it has been observed that self-reports of weight and height by females are more consistent with objectives measures. [44] Although there were no statistically significant differences in BMI, the proportion of respondents who were overweight had decreased at follow-up. Figures for our sample were lower than national prevalence figures, which show that $22 \%$ of men and $24 \%$ of women are obese, and that $34 \%$ of men and $33 \%$ of women are overweight. [45] 
While there is a possibility of under-reporting or sample bias, it should be recognised that there remained a significant proportion of employees who self-reported that they were either overweight or obese. Although daily consumption of sugary foods was lower at follow-up, there were no other significant changes in reported dietary behaviours. It is of concern that a significant proportion of our employees did not consume a healthy diet (e.g. 5 a day), even though the majority perceived that they ate healthily at the time of reporting. Although our wellness programme included a number of interventions targeted to dietary habits across the five years (e.g. weight management classes, 'smoothie' bar, improved food in catering facilities), diet was not the primary focus of the programme and these findings clearly highlight a need for increased health education and dietary-focused intervention to increase the proportion of employees who consume a healthy diet and encourage a healthy weight in the NHS workforce. In practice, efforts have been made to increase the focus on diet and weight management within this setting, and indeed, our findings have shown both an increase in use of the catering facilities onsite, and in those who access the facilities, an improvement in attitudes over the five years towards the availability of healthy food options in the workplace.

While the response rate was relatively low, it is satisfactory for a survey of such magnitude since the baseline response rate was greater than that achieved in other large employee surveys. [46] Furthermore, the baseline and five-year surveys generated responses from a sample that was broadly representative of the target population. However, the generalisability of the study findings may be limited by the lack of analysis of individual-level changes in health behaviours, and also by the fact that respondents were self-selected and were on the whole more physically active than the general population. While we have not demonstrated whether our respondents 
exhibited improved health behaviours compared with non-responders, or whether they were a more motivated group, it should be recognised that responders included both users and non-users of the programme.

Although the study design itself limits the ability to determine causality with the most scientific rigour, meeting the basic criteria for randomised design in 'real- world' research can be challenging. [30] Previous studies successfully employing such designs have often been based on individual interventions narrowly focused on single outcomes and objectives, such as changing a specific health behaviour (e.g. physical activity) via a specific means (e.g. single environmental initiative) in a manageable setting (e.g. an unchanging environment). In this instance, the intervention developed over a period of several years in a climate of extensive organisational change, with a trust merger resulting in a substantial increase in population size with the addition of a new hospital site, high staff turnover and a need to develop new facilities and services to serve additional staff in a new location, while wellbeing activities at the original site had already been established and running for some time. This also resulted in a need to recruit and train additional health champions.

However, this award-winning intervention was strengthened by a clear conceptual basis in the ecological model of health that has an evidence base for positive outcomes in health behaviour interventions. [21,47] Work is currently being undertaken to further investigate those aspects of the intervention that met with success or failure, and the correlates, determinants and mediators of workplace wellness programme participation and adherence. Although this intervention was adopted by the local NHS trust to become an ongoing service for employees, further research is warranted to demonstrate the cost-benefit of such programmes. 


\section{CONCLUSION}

This work demonstrates that workplace interventions are achievable in NHS workplace settings, and confer positive outcomes in those organisations where employers demonstrate a commitment to health and wellness that is fully integrated with their mission, values and long-term vision. The impact of even small-to-moderate improvements in health behaviours is substantial and renders the worksite as a setting in which it is clearly feasible to continue to promote wellbeing, and is sustainable over many years. However, to generate significant behaviour change in a range of target health behaviours, such schemes need to be flexible and continually responsive to its consumers; as such it should be recognised that wellness programmes require continual adjustment to alter the targeting of activities in response to user need.

\section{ACKNOWLEDGEMENTS}

The authors would like to thank all those involved in the design, delivery and management of the intervention; in particular, Steph Knowles, Dr Sandra Lee, Mr Daniel Mortimer and Christine Woolley. The intervention was supported by Sport England and the Big National Lottery with an 'Active England' grant.

\section{REFERENCES}

1 World Health Organisation (WHO). Healthy Workplaces: A Model for Action. Geneva: WHO, 2010

2 Department of Health. Choosing Health: Making Healthy Choices Easier. London: The Stationery Office, 2004

3 Department of Health. NHS Health and Wellbeing Review: Interim Report. London: The Stationery Office, 2009 
4 Batt ME. Physical activity interventions in the workplace: the rationale and future direction for workplace wellness. British Journal of Sports Medicine 2009; 43: 47-48 5 Kwak L, Kremers SPJ, Van Baak MA, Brug L. Participation rates in worksite-based intervention studies: health promotion context as a crucial quality criterion. Health Promotion International 2005; 21: 66-9

6 Blake H, Lloyd S. Influencing organisational change in the NHS: lessons learned from workplace wellness initiatives in practice. Quality in Primary Care 2008; 16 : $449-55$

7 Bull FC, Adams E, Hooper PL. Well@Work:

Promoting Active and Healthy Workplaces. Final Evaluation Report. Loughborough: School of Sport and Exercise Sciences, Loughborough University, 2008 8 Mills PR, Kessler RC, Cooper MD, Sullivan S. Impact of a health promotion program on employee health risks and work productivity. American Journal of Health Promotion 2007; 22: 45-53

9 Lee $\mathrm{S}$, Blake H, Lloyd S. The price is right: mak- ing workplace wellness financially sustainable. International Journal of Workplace Health Management 2010; 3: $58-69$

10 NHS Information Centre. Sickness absence rates of NHS staff in 2005. Available online at: http://www.hscic.gov.uk/catalogue/pub01951 (Last accessed 25th April 2013)

11 Blake H, Mo PKH, Lee S, Batt ME. Health in the NHS: lifestyle behaviours of hospital employees. Perspectives in Public Health 2012; 132: 213-15

12 Blake H, Malik S, Mo PKH, Pisano C. 'Do as I say, but not as I do': are next generation nurses role models for health? Perspectives in Public Health 2011; 131: $231-9$ 
13 Malik S, Blake H, Batt ME. How healthy are our nurses? New and registered nurses compared. British Journal of Nursing 2011; 20: 489-96

14 Blake H. Should nurses be role models for health? Nursing Times, 2 January 2013 Available online at: http://www.nursingtimes.net/holly- blake-should-nurses-be-rolemodels-for- health/5052877.article?blocktitle $=$ Health-promotioncoverage \&contentID=1603 (Last accessed 25th April 2013)

15 Connolly MA, Gulanick M, Keough V, Holm K. Health practices of critical care nurses: are these nurses good role models for patients? American Journal of Critical Care 2008; 16: 261-6

16 Kutlu R. Evaluation of the frequency and factors affecting smoking among nurses. Gulhane Medical Journal 2008; 50: 65-70

17 Shanafelt TD, Bradley KA, Wipf JE, Back AL. Burnout and self-reported patient care in an internal medicine residency program. Annals of Internal Medicine 2002; 136: $358-67$

18 Firth-Cozens J. Interventions to improve physi- cians' well-being and patient care. Social Science and Medicine 2001; 52: 215-22

19 McDowell N, McKenna J, Naylor PJ. Factors that influence practice nurses to promote physical activity. British Journal of Sports Medicine 2007; 31: 308-13 20 Sallis JF, Owen N. Ecological models of health behaviour. In K Glanz, BK Rimer, FM Lewis (eds) Health Behavior and Health Education: Theory, Research, and Practice, 3rd edn. San Francisco, CA: Jossey-Bass, 2002 21 Sallis JF, Cervero RB, Ascher W et al. An ecological approach to creating active living communities. Annual Review of Public Health 2006; 27: 297-322 
22 Blake H, Chambers D. Supporting nurse health champions: developing a 'new generation' of health improvement facilitators. Health Education Journal 2011. DOI: $10.1177 / 0017896910396767$

23 Craig CL, Marshall AL, Sjostrom M et al. International physical activity questionnaire: 12-country reliability and validity. Medicine \& Science in Sports \& Exercise 2003; 35: 1381-95

24 Goldberg DP, Williams P. A User's Guide to the General Health Questionnaire. Windsor: NFER- Nelson, 1998

25 Allender S, Peto V, Scarborough P et al. Coronary Heart Disease Statistics. London: British Heart Foundation, 2007

26 US Department of Health and Human Services (USDHHS). Physical Activity and Health: A Report of the Surgeon General. Atlanta, GA: USDHHS, 1996

27 Hamilton MT, Hamilton DG, Zderic TW. Role of low energy expenditure and sitting in obesity, metabolic syndrome, type 2 diabetes, and cardiovascular disease. Diabetes 2007; 56: 2655-67

28 Hutchinson AD, Wilson C. Improving nutrition and physical activity in the workplace: a meta- analysis of intervention studies. Health Promotion International $2012 ; 27: 238-49$

29 Hess I, Borg J, Rissel C. Workplace nutrition and physical activity promotion at Liverpool Hospital. Health Promotion Journal of Australia 2011; 22: 44-50 30 McEachan RR, Lawton RJ, Jackson C et al. Testing a workplace physical activity intervention: a cluster randomized controlled trial. International Journal of Behavioral Nutrition and Physical Activity 2011; 8: 29. 
31 Jones $\mathrm{CH}$, Ogilvie D. Motivations for active commuting: a qualitative investigation of the period of home or work relocation. International Journal of Behavioral Nutrition and Physical Activity 2012; 9: 109.

32 Taylor CB, Coffey T, Berra K et al. Seven-day activity and self-report compared to a direct measure of physical activity. American Journal of Epidemiology 1984; 120 : $818-24$

33 Mo PKH, Blake H, Batt ME. Getting healthcare staff more active: the mediating role of self- efficacy. British Journal of Health Psychology 2011; 16: 690-706 34 Buck D, Frosini F. Clustering of Unhealthy Behaviours over Time: Implications for Policy and Practice. London: The Kings Fund, 2012

35 Fletcher GM, Behrens TK, Domina L. Barriers and enabling factors for work-site physical activity programs: a qualitative examination. Journal of Physical Activity and Health 2008; 5: 418-29

36 Office for National Statistics (ONS). General Household Survey: Smoking and Drinking among Adults. London: ONS, 2007

37 Smokefree England. A healthier England from July 1st 2007. London: Smokefree England, 2007

38 Arack R, Blake H, Lee S, Coulson NS. An evaluation of the effects of the smoking ban at an acute NHS trust. International Journal of Health Promotion and Education $2009 ; 47: 112-8$

39 NHS Information Centre. Sickness absence rates in the NHS: January - March 2011. Available online at: http://www.ic.nhs.uk/pubs/ absenceratesmar11 (Last accessed 25th April 2013) 40 Blaber AY. Exercise: who needs it? British Journal of Nursing 2005; 14: 973-5 
41 Voss M, Stark S, Alfredsson L et al. Comparisons of self-reported and register data on sickness absence among public employees in Sweden. Occupational and Environmental Medicine 2008; 65: 61-7

42 Berry LL, Mirabito AM, Baun WB. What's the hard return on employee wellness programs? Harvard Business Review 2010; 88: 104-12, 142

43 Pronk NP, Kottke TE. Physical activity promotion as a strategic corporate priority to improve worker health and business performance. Preventive Medicine 2009; 49: $316-21$

44 Lois K, Kumar S, Williams N, Birrell L. Can self- reported height and weight be relied upon? Occupational Medicine 2011. DOI: $10.1093 /$ occmed/kqr140 45 Department of Health. Healthy Weight, Healthy Lives: One Year On. London: The Stationery Office, 2009

46 Prodaniuk TR, Plotnikoff RC, Spence JC. The influence of self-efficacy and outcome expectations on the relationship between perceived environment and physical activity in the workplace. International Journal of Behavioral Nutrition and Physical Activity 2004; 1: 7.

47 Warren BS, Maley M, Sugarwala LJ et al. Small steps are easier together: a goalbased ecological intervention to increase walking by women in rural worksites. Preventive Medicine 2010; 50: 230-4 
Tabla 2

Demographic data at baseline and five-year follow-up

Variables

Gender

Marital status

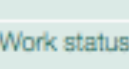

Distance to work
Timeline

Male

Fernale$$
\text { Female }
$$

Sinporise separate tron

Single or live separate from partner

Whe with pertnerispouse

Lve with partner/spouse

\begin{tabular}{|l|l|}
\hline \\
\hline
\end{tabular}

$$
\text { Full-time }
$$

Part-time

$$
\text { Part-time }
$$

\section{Timeline}

Basaline

Follow-up

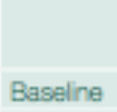

Follow-up

Baseine

\section{Baseine}

Folow-up

Baseine

Baseline n

ran

297

297

Folow-up

264

1,15

1,155
854

|

434

364

30.3

Folow-up

996

Folow-up

996
749

32.7

Folow-

\begin{tabular}{|l|l}
749 & 67.30 \\
\hline
\end{tabular}

Baseline

1024

Folow-up

416

71.11

28.89

\begin{tabular}{|l|r|}
\hline Baseine & 834 \\
\hline Folow-up & 300
\end{tabular}

300

\begin{tabular}{l|l}
\hline 834 & 73.54 \\
\hline 300 &
\end{tabular}

26.46

SD

\begin{tabular}{|l|l|}
\hline 41.06 & 11.24 \\
\hline 41.65 & 11.48 \\
\hline
\end{tabular}

$\frac{t}{-1.27}$

df

p

$-1.27$

2514

.203

11.48

$-1.21$

2482

228 


\begin{tabular}{|c|c|c|c|c|c|}
\hline \multicolumn{6}{|c|}{$\begin{array}{l}\text { Analysis of varianoes for physical activity and insetivity, sel-etticacy, social support, job satistaction and arganisational } \\
\text { commitment }\end{array}$} \\
\hline & Souree & of & $\boldsymbol{F}$ & $p$ & Partial $\pi^{2}$ \\
\hline \multirow[t]{4}{*}{ Incidertal physical activity } & Corrected model & 4. 2287 & 43.65 & $<.001 \cdots$ & 0.071 \\
\hline & Tme & 1, 2287 & 56.53 & $<.001 \cdots$ & 0.024 \\
\hline & Activerness & 2, 2287 & 50.18 & $<.001 \cdots$ & 0.042 \\
\hline & Tme' Activeness & 1,2287 & D.ecc3 & .44 & \\
\hline \multirow[t]{3}{*}{ Sports and rocruostond activty } & Corroctod modd & & & & \\
\hline & Tme & 1,2581 & 3.76 & .053 & \\
\hline & Activerness & 2. 2581 & 43.75 & $<.001 \cdots$ & 0.033 \\
\hline \multirow{4}{*}{$\begin{array}{l}\text { Time spert siting for beth work and } \\
\text { non-work }\end{array}$} & Conected Modsl & 4. 2149 & 10.75 & $<.001 \cdots$ & 0.18 \\
\hline & Tma & 1,2149 & 4.87 & $<.001 \cdots$ & 0.140 \\
\hline & Activeness & 2,2149 & 3.64 & $.026^{\circ}$ & 0.003 \\
\hline & Timn' Activenoss & 1,2149 & E.41 & $.011^{\circ}$ & 0.003 \\
\hline \multirow{4}{*}{$\begin{array}{l}\text { Time soers moving about for beth } \\
\text { work and non-wok }\end{array}$} & Corrected modsl & 4. 2149 & 5.10 & $<.001^{\cdots}$ & 0.14 \\
\hline & Tme & 1,2148 & 8.78 & $<.001^{\cdots}$ & 0.17 \\
\hline & Activeness & 2,2149 & 1.72 & .180 & \\
\hline & Time' Activeness & 1,2149 & 3.06 & cosi & \\
\hline \multirow[t]{4}{*}{ Solt-eflency for physical activity } & Corrocted model & 4,2506 & 109.31 & $<.001^{m}$ & 0.149 \\
\hline & $\operatorname{Tm} \theta$ & 1,2505 & 0.126 & .72 & \\
\hline & Activeness & 2,2505 & 21433 & $<.001^{\cdots}$ & $0.1<\theta$ \\
\hline & Tme $\cdot$ Activeness & 1,2505 & 0.002 & .87 & \\
\hline \multirow[t]{4}{*}{ Knowhodge sbous phyejal activity } & Combeted model & 4,2530 & 0.08 & .998 & \\
\hline & Time & 1,2530 & 0.03 & .802 & \\
\hline & Activeness & 2, 2530 & 0.29 & .590 & \\
\hline & Tme ${ }^{*}$ Activeness & 1,2530 & 0.003 & .997 & \\
\hline \multirow[t]{4}{*}{ Setl-eficacy for hes thy eeting } & Corrected modsl & 4,2407 & 0.96 & 42 & \\
\hline & Time & 1,2407 & 0.01 & .94 & \\
\hline & Activenesz & 2,2407 & 1.86 & .16 & \\
\hline & Time' Retvoness & 1,2407 & 0.04 & 84 & \\
\hline \multirow[t]{4}{*}{ Supoot for physicel activity } & Correcsed modsl & 4,2028 & 14.82 & $<, 001 \cdots$ & 0.029 \\
\hline & Tme & 1,2028 & 1.65 & 20 & \\
\hline & Activenesz & 2,2028 & 26.37 & C.COI $=$ & 0.025 \\
\hline & Tme' Retiveness & 1, 2028 & 1.35 & 25 & \\
\hline & & & & & (bonthuod) \\
\hline
\end{tabular}


Table 3 (continued)

\begin{tabular}{|c|c|c|c|c|c|}
\hline & Source & df & $\boldsymbol{F}$ & p & Partial $\eta^{2}$ \\
\hline \multirow[t]{4}{*}{ Support for healthy eating } & Corrected model & 4,2050 & 3.55 & $.007^{\star \star}$ & 0.01 \\
\hline & Time & 1,2050 & 0.10 & .76 & \\
\hline & Activeness & 2,2050 & 6.96 & $<.001^{\star \star \star *}$ & 0.007 \\
\hline & Time * Activeness & 1,2050 & 0.00 & .96 & \\
\hline \multirow[t]{4}{*}{ Job satisfaction } & Corrected model & 4,2529 & 7.37 & $<.001^{\star \star \star}$ & 0.012 \\
\hline & Time & 1,2529 & 11.03 & $.001^{\star \star}$ & 0.004 \\
\hline & Activeness & 2,2529 & 7.68 & $<.001^{\star \star \star}$ & 0.006 \\
\hline & Time * Activeness & 1,2529 & 0.80 & .37 & \\
\hline \multirow[t]{4}{*}{ Commitment to NHS } & Corrected model & 4,2301 & 2.49 & $.042^{*}$ & 0.004 \\
\hline & Time & 1,2301 & 5.70 & $.017^{*}$ & 0.002 \\
\hline & Activeness & 2,2301 & 0.77 & .462 & \\
\hline & Time * Activeness & 1,2301 & 2.05 & .152 & \\
\hline
\end{tabular}




\begin{tabular}{|c|c|c|c|c|c|}
\hline \multicolumn{6}{|c|}{ Comparison of commonly reported barriers at baseline and follow-up } \\
\hline Barriers & Timeline & $\boldsymbol{n}$ & $\%$ & $\phi$ & $\boldsymbol{p}$ \\
\hline \multirow[t]{3}{*}{ Lack of time } & & & & -0.04 & $.03^{*}$ \\
\hline & Baseline & 909 & 62.62 & & \\
\hline & Follow-up & 650 & 57.31 & & \\
\hline \multirow[t]{3}{*}{ Being too tired } & & & & -0.01 & .22 \\
\hline & Baseline & 495 & 34.11 & & \\
\hline & Follow-up & 370 & 32.62 & & \\
\hline \multirow[t]{3}{*}{ Lack of motivation } & & & & -0.009 & .29 \\
\hline & Baseline & 344 & 23.71 & & \\
\hline & Follow-up & 276 & 24.30 & & \\
\hline \multirow[t]{3}{*}{ Need to rest and relax } & & & & -0.019 & .16 \\
\hline & Baseline & 321 & 22.13 & & \\
\hline & Follow-up & 260 & 19.42 & & \\
\hline${ }^{*} p<.05$ & & & & & \\
\hline
\end{tabular}

